\title{
PLANEJAMENTO ESTRATÉGICO, ENERGIAS LIMPAS E ALTERAÇÕES CLIMÁTICAS NO CONTEXTO DA MUDANÇA DE PARADIGMAS
}

\author{
Fernando José Pereira da Costa \\ Universidade de Santiago de Compostela \\ Manoel Gonçalves Rodrigues \\ Observatório Urbano/UERJ/UN-Habitat
}

\section{RESUMO}

No contexto da Primeira Revolução Industrial tem início o Paradigma Energético-Ambiental dos Combustíveis Fósseis. No princípio, o combustível fóssil base de toda a matriz energéticotecnológico-produtiva era o carvão, que passa a ser deslocado pelo petróleo, e já bem mais tarde passa-se a valer do gás natural. O Paradigma dos Combustíveis Fósseis começa a entrar em crise na década de 1970, com a ocorrência dos choques petrolíferos de 1973 e 1979. Começam então a surgir os sinais da emergência de um novo paradigma, a saber: 0 Paradigma das Fontes Renováveis de Energia. Entretanto, decorridas mais de três décadas, o novo paradigma mostra-se ainda longe de se apresentar como hegemônico. O que acontece é que vive-se, de fato, um período de transição paradigmática do Paradigma dos Combustíveis Fósseis para o Paradigma das Fontes Renováveis de Energia, o qual deverá durar ainda várias décadas, representando uma fase de transformações técnico-produtivas, de incorporações de inovações a nível da tecnologia, de novas configurações energo-tecnológicas e da interação entre energéticos dominantes e fontes não convencionais de energia, buscando-se averiguar, neste contexto, a questão das mudanças climáticas.

Palavras-Chave: Planejamento Estratégico, Mudanças Climáticas, Paradigmas

\begin{abstract}
In the context of the First Industrial Revolution opened the Energy and Environmental Fossil Fuels Paradigm. The basis of all fossil fuel energy matrix-technological-productive was the coal that is being displaced by oil, and now spends much later to draw on natural gas. The Paradigm of Fossil Fuels is entering a crisis in the 1970s, with the occurrence of the oil shocks of 1973 and 1979. They then begin to appear the signs of the emergence of a new paradigm, namely the Paradigm of Renewable Energy Sources. However, more than three decades elapsed, the new paradigm appears to be still far from presenting itself as hegemonic. Therefore, a period of paradigmatic transition Fossil Fuels Paradigm for the other one supported by Renewable Energy Sources, which should last several more decades, representing a stage of technicalproductive transformations, mergers innovations in the technology, new energy-technological configurations and the interaction energy between dominant and non-conventional sources of energy, trying to find out in this context, the issue of climate change.
\end{abstract}

Keywords: Strategic Planning, Climate Change, Paradigms 


\section{INTRODUÇÃO}

Na Primeira Revolução Industrial (PRI), ocorrida na Inglaterra entre os séculos XVIII e XIX, configurou-se o Paradigma dos Combustíveis Fósseis, primeiramente baseado no carvão e, mais tarde, principalmente após a Segunda Guerra Mundial, tomando-se o petróleo como energético diretor. Este paradigma baseava-se num modelo de elevado nível de voracidade energética com profundos impactos sobre o meio ambiente. A ocorrência dos choques petrolíferos da década de 1970 começa a mostrar as debilidades e aspectos perversos do modelo que caracterizaria o Paradigma dos Combustíveis Fósseis. Ao se abordar a questão Energético-Ambiental e os aspectos a ela relacionados não se a deve considerar como um bloco monolítico, o que faria com que o observador menos atento viesse a passar ao largo da sua enorme diversidade, fruto da inserção/interação com distintos meios e configurações ecossistêmicas. Para além de considerar as características dos distintos cenários de atuação/aplicação da questão Energético-Ambiental, há que se levar em conta que o tratamento da mesma só ganha sentido no contexto da Public Policy, a qual, por sua vez, deve posicionar-se, de forma sistêmicointerativa e dinâmico-sinérgica, face à própria Política Ambiental e à própria Política Energética e relativamente às demais esferas da Política Pública (econômica, industrial, científica, tecnológica,).

Portanto, afirma-se que somente, no contexto das Políticas Públicas é que a a abordagem da questão Energético-Ambiental ganha relevo e obtem justificação/legitimação. Assim sendo, a abordagem da questão EnergéticoAmbiental, do ponto de vista sistêmico-dinâmico-interativo, implica em adotar, como componente teórico-metodológica, a concepção de que a questão ambiental não pode ser considerada como um universo isolado. Isto fica mais notório quando se advoga que desde os choques petrolíferos da década de setenta, mais precisamente em 1973 e 1979, passou-se a viver uma fase de transição entre paradigmas energéticos-ambientais e sócio-civilizacionais. Deste modo, assiste-se, desde os anos setenta do século XX, à passagem do Paradigma dos Combustíveis Fósseis ao Paradigma das Fontes Renováveis de Energia, questão que, por seu lado, não se prende apenas à questão energética, mas simultaneamente/interativamente à questão ambiental.

A partir daí tem início um processo de transição para um novo paradigma energético-ambiental, a saber: o Paradigma das Fontes Renováveis de Energia, no qual estas assumam uma importância estratégica a nível da base técnico-econômico-produtiva e em termos da construção de uma matriz energética sustentável, tendo como pano de fundo as questões ambientais. Assim sendo, a política econômica deverá passar a interagir sistematicamente com a política energética e com a política ambiental, através da gestão estratégica da matriz energética e da construção de uma matriz energética sustentável, bem como com outras esferas da política pública tecnológica, 
industrial, agrícola, etc., numa perspectiva efetivamente sistêmica. Em outras palavras, a transição de paradigmas a nível energético-ambiental implicará numa postura sistêmico-estratégica, e de caráter gestionário-organizacionalplanificatório, que se traduza por uma intervenção sobre a base produtiva e a construção de uma matriz energética sustentável. Para isto, torna-se necessário implementar a gestão estratégica da matriz energética, buscando sua diversificação e fazendo crescer, de forma significativa, a participação das fontes energéticas renováveis, isto é, os energéticos diretores do novo paradigma.

\section{PARADIGMA DAS FONTES RENOVÁVEIS DE ENERGIA}

A PRI teve como energético básico o carvão e se afirma com a entrada em cena do petróleo, que em razão de uma série de aspectos favoráveis tai como ser um combustível líquido de manuseio relativamente fácil, a dispor de reservas amplas e a um preço de mercado reduzido, e que se converteria no energético diretor da Segunda Revolução Industrial (SRI), a suportar um modelo de crescimento consumista, energívoro e energodesperdiçador. A Terceira Revolução Industrial (TRI), que tem início em princípios dos anos setenta do século XX, coincidindo (e acelerando-a) com a crise do Welfare State (provavelmente a sua débâcle) e com a hegemonia das teses neoliberais, caracteriza-se pela introdução de um imenso manancial de inovações de índole científico-tecnológica. Na verdade, conforme registra CHIAVENATO (1993, pp. 20 e 21), todo esse processo seria marcado pelo surgimento de tecnologias genuinamente novas e não apenas pelo simples desdobramentos de tecnologias já existentes, com a crescente aceleração da transformação da tecnologia em produto/serviço prontamente disponível para utilização e consumo.

A SRI marca também o estabelecimento da energia termonuclear. No final da SRI e princípios da TRI, na concepção deste trabalho mais adequadamente denominada de Terceira Revolução Industrial e Tecnológica (TRIT), por ser a mais tecnológica das Revoluções Industriais, na qual a interação entre a componente científico-técnica e a base industrial alcança um nível nunca antes visto, entra em cena o gás natural. Este, também um combustível fóssil, não renovável e poluente (embora menos que o petróleo e o carvão) passa a constituir uma fileira energética inovadora/sofisticadora a nível de processos, equipamentos e usos finais, com nítidas consequências em termos de avanço tecnológico. Contudo, apesar dos ganhos energético-tecnológico-produtivos, o gás natural não representava uma ruptura com o paradigma dominante.

Contudo, já em finais da SRI e princípios da TRIT, começa a se difundir a utilização energético-técnico-produtiva das fontes renováveis. A 
hidroeletricidade já era há muito utilizada, malgradas as restrições/condicionamentos a ela impostas, principalmente no caso dos países da Periferia/Semiperiferia, a partir da década de oitenta do século XX, fazendo com que um país como o Brasil, por exemplo, aproveite pouco mais de $20 \%$ do seu potencial hídrico. O manancial de fontes renováveis de energia começa a se apresentar, quer a nível de estudos/pesquisas, quer em termos de uso efetivo. As opções energéticas alternativas são diversas (solar, eólica, marés, biomassa, reciclagem, aproveitamento dos resíduos sólidos, etc.), começam a mostrar-se competitivas face aos combustíveis fósseis e surgem como base energético-tecnológica de um novo paradigma energético-ambiental, a saber: o Paradigma das Energias Renováveis. Contudo, ao contrário das expectativas extremamente otimistas/voluntaristas afetas ao approach ecológicofundamentalista, ainda se encontra longe o tempo em que se completará a transição paradigmática em termos energéticos-ambientais e se consolidará, de forma definitiva, o novo paradigma dominante, qual seja, o Paradigma das Fontes Renováveis de Energia.

O período de transição paradigmática será lento (horizonte temporal de longo prazo), com a utilização conjunta de combustíveis fósseis e energéticos renováveis, com a complementaridade entre eles e com a interação/interpenetração dessas duas modalidades energo-tecnológicoambientais. A fase de transição paradigmática em termos energéticoambientais já está a ter, como elemento básico de caracterização, a gestão estratégica da matriz energética, não somente no sentido de reduzir a participação dos petroderivados, mas também no que se refere ao aumento relativo dos energéticos renováveis e à diminuição da dependência de fluxos externos de abastecimento de energia. O longo período da transição paradigmática em termos energéticos-ambientais será marcado por uma intensa/dinâmica atuação do binômio «Energia/Tecnologia», com os avanços científico-técnicos e as inovações tecnológicas criando e viabilizando a utilização de fontes não convencionais de energia. Logo, a mudança ocorre a nível do paradigma energético-ambiental. Portanto, é neste contexto que se deve ter a Educação Ambiental como instrumento de estudo e de preparação e conscientização da sociedade, mormente das gerações que viverão este processo de forma mais intensa e presente.

Como é observado por SINGER (1998, pp. 173 e 174), a ocorrência da TRI/TRIT coincide com a entrada em cena da implementação do projeto neoliberal (ou contra-revolução neoliberal). Em outras palavras, a TRI/TRIT começa a dar os seus primeiros passos em inícios/meados da década de 1970. É nessa época que se aperfeiçoa o microcomputador, barateando a computação e tornando-a mais acessível aos negócios e a maior parte dos consumidores. Houve, a partir daí, uma expansão/difusão acelerada da tecnologia digital a todo o tipo de trabalho industrial, nos serviços e nas 
atividades agrícolas, o que proporcionaria a obtenção de elevados e crescentes ganhos de produtividade do trabalho. A automação, através do aperfeiçoamento dos robôs deu saltos gigantescos, viabilizando a substituição da força humana de trabalho até mesmo em atividades a exigir inteligência elementar. Assim sendo, seria de se esperar que a TRI/TRIT, enquanto revolução infra-estrutural, levasse à aceleração do crescimento da economia capitalista mundial. Contudo, tal não se verificaria, uma vez que a desaceleração do crescimento, por parte das economias capitalistas centrais, do início dos anos 1970 a meados da década de 1990, mostrou-se como algo verdadeiramente impressionante.

Portanto, SINGER (1998, p. 174 e 175) observa que existe um claro descompasso entre a aceleração do progresso tecnológico e a desaceleração do crescimento econômico, uma vez que este último irá depender muito mais da evolução da demanda efetiva do que do avanço da tecnologia. Na verdade, o que ocorre é que as atividades econômicas, em diferentes momentos, valemse de tecnologias oriundas de vários estágios geracionais, enquanto somente uma determinada fração da produção surge como resultado da utilização de tecnologias mais recentes, resultantes do processo de inovação. O que ocorre é que a coexistência de diferentes estágios tecnológicos implica em diferentes produtividades e custos de produção e isto pode ser explicado por diversos fatores. Em primeiro lugar, há que considerar que os mercados dos produtos não são perfeitos e que a mesma mercadoria pode ser posta a venda, em mercados distintos, por preços diferentes, com o grau de acessibilidade, por exemplo, influenciando o nível de preços. Depois, tem de se levar em conta que os salários não são iguais em todos os lugares e que as empresas que recorrem a tecnologias mais antigas são as que pagam menores salários, compensando os menores níveis de produtividade via um menor custo da força de trabalho.

Para além disso, a qualidade dos produtos também não é uniforme. A questão é que o crescimento da economia conduz a um mais rápido/vigoroso processo de atualização/substituição tecnológica (substituição das tecnologias obsoletas por outras mais modernas), o que conduz ao crescimento da produtividade, sem que necessite ocorrer, necessariamente, o avanço das melhores técnicas. Já a recessão, por seu lado, conduz à desaceleração da atualização tecnológica, sendo possível a quebra de empresas que mosrem defasagem tecnológica, bem como de outras que tenham recorrido ao endividamento para promover o reequipamento. Na recessão, as inversões tendem a cair em razão da superprodução, que atua como elemento de desestímulo ao investimento produtivo. Na verdade, o que se observa é que TRI/TRIT, no caso das economias capitalistas centrais, não consegue reverter o quadro recessivo existente, o que poderia significar que os ganhos de produtividade potenciais 
por ela possibilitados teriam sido muito pouco aproveitados num contexto de pouco dinamismo e semi-estagnação das economias centrais.

De fato, há que registrar a acelerada exportação de capitais para a Periferia/Semiperiferia, notadamente para as economias asiáticas, dotadas de maior dinamismo e de sistemas dirigistas estatal-planificadores. Por outro lado, cabe assinalar que as multiempresas adotam as novas tecnologias (notadamente a nível da automação) com um certo grau de rapidez. Contudo, é provável que muitas empresas tenham crescido os seus níveis de produtividade valendo-se de tecnologias mais antigas e salários mais baixos, 0 que teria ocorrido não somente nos países centrais, mas também nas economias periféricas/semiperiféricas. Neste ponto pode-se mesmo arriscar que no caso das áreas dinâmicas da Periferia/Semiperiferia (a dispor de sistemas estratégico-planificadores), possa ter havido uma combinação de inovações tecnológicas (típicas da TRI/TRIT) com níveis relativamente mais baixos de salários, o que conduziria a elevados saltos a nível da produtividade. Em função disso, não seria exagero levantar a hipótese de que o potencial transformador da TRI/TRIT estaria sendo realizado nas economias periféricas/semiperiféricas da Ásia, cujo dinamismo poderia ser em parte justificado pelo estatal-dirigismo, configurado pela existência de um efetivo planejamento estratégico.

Caberia assinalar que SANTOS (1983, pp. 24 - 32) apresenta o conceito de Revolução Científico-Técnica (RCT), que é desencadeada a partir do processo de automação, cujo processo de aplicação tem início na década de 1950, deixando a ciência de ser um elemento auxiliar do processo produtivo para se tornar parte deste e da própria atividade produtiva, a qual, por sua vez, converte-se em ramo aplicado da atividade científica. Com a RCT, o homem não tem que auxiliar a máquina (como na $P R I$ e na SRI) e se separa quase que completamente de todas as etapas afetas ao processo produtivo que requeriam sua intervenção direta. $\mathrm{Na}$ verdade, de um ponto de vista estritamente mecânico, a automação (processo intimamente ligado ao desenvolvimento da computação eletrônica, muito embora a ele não limitado) está promovendo a substituição de séries de máquinas individuais por um sistema completo de processos integrados, o que poderia representar a superação da era da Revolução Industrial (com este conceito, esta análise engloba a PRI e a SRI, categorias adotadas por este trabalho) e a entrada num novo estágio de civilização.

Assim sendo, de acordo com o que é registrado por SANTOS (1983, pp. 39 e 40), a computação industrial cria recursos tecnológicos consideráveis e a utilização dos mesmos se constitui em resposta às necessidades do capital e dos processos de acumulação e reprodução deste último, o que faz com que as tarefas de gestão sejam aquelas sobre as quais recaem as principais 
atenções da computação. Deste modo, embora as empresas monopolistas busquem exercer o controle crescente das atividades englobadas pela computação, elas não poderão controlar todas as consequências (econômicas, sociais e políticas) da aplicação da automatização. A automação/computação aplicam-se à produção (indústria aeronáutica e espacial), à gestão da produção, ao design, à gestão empresarial, aos sistemas de controle produtivogerenciais, etc.

Os conceitos de TRI/TRIT e de RCT aplicam-se a conceitos, periodizações e concepções diferentes. $O$ conceito de TRI/TRIT parte do princípio que não houve apenas uma Revolução Industrial, mas sim três Revoluções Industriais, ocorridas em momentos históricos distintos e em diferentes etapas do desenvolvimento do capitalismo industrial, correspondendo a mudanças profundas a nível da base produtivo-industrial e da estrutura organizativoempresarial-administrativa. A TRI/TRIT é desencadeada em inícios/meados dos anos 1970 e tem como característica um conjunto de profundas transformações a ocorrer a nível tecnológico. De fato, a TRI/TRIT é a mais tecnológica das Revoluções Industriais. Por seu lado, a RCT desencadeia-se a partir dos anos 1950 com o desenvolvimento da automação e se aprofunda com a expansão da computação a nível da esfera da produção e da componente organizativo-gerencial da economia. Se o conceito de TRI/TRIT parte da concepção da existência de três Revoluções Industriais, o de RCT considera a Revolução Industrial como única, quando muito admitindo que a RCT poderá conduzir a uma segunda Revolução Industrial. Na verdade, a concepção de Revolução Industrial afeta à RCT abarca a PRI e a SRI. A questão está em saber se os dois conceitos (a saber: TRI/TRIT e RCT) são passíveis de algum tipo de compatibilização. De acordo com a visão deste trabalho, pode se pensar na possibilidade de consolidar e interagir os dois conceitos, pelo fato de que se passaria a considerar a RCT a ocorrer nas últimas duas décadas da SRI, acabando o seu desenvolvimento a conduzir ao desencadeamento/aprofundamento da TRI/TRIT. Com isto, não só se conseguiria conciliar/interagir os dois conceitos, como situar, em termos teórico-conceituais e metodológicos, a RCT como fator de dinamização/viabilização do intenso progresso tecnológico desencadeado no estágio superior da SRI, bem como do elevado e acentuado nível de incorporação tecnológica verificado no contexto da TRI/TRIT atualmente em vigor.

$\mathrm{Na}$ verdade, cada revolução industrial produz um reordenamento dos processos competitivos, fruto da inovação e do avanço tecnológico, que conduzem a mudanças na função de produção. Na PRI, há a destacar a máquina a vapor, principalmente a partir do momento em que os engenhos mecânicos passam a valer-se do ferro para o seu fabrico (máquinasferramentas) e, a nível dos bens de consumo, os têxteis. Na verdade, de 
acordo com a perspectiva de CAZADERO (1995, pp. 9 e 10), no que se refere à análise da industrialização das sociedades, a mesma não deve ser tomada como um processo linear, antes devendo contemplar períodos de continuidade e fases de ruptura, aí inserindo-se o conceito de Revolução Industrial. Assim sendo, rechaça-se completamente a idéia de que o processo industrializador constituiu-se em um processo ininterrupto desde a segunda metade do século XVIII até o presente momento. Portanto, cada Revolução Industrial produz um período de desenvolvimento que termina por entrar em crise ao se esgotarem as capacidades dinamizadoras da base tecnológica que a sustenta, bem como do sistema institucional que a regula.

Assim sendo, a transição entre o Paradigma dos Combustíveis Fósseis e o Paradigma das Fontes Renováveis de Energia, para além de assumir um carácter claramente de longo prazo, começa a ocorrer na SRI e prossegue seu caminho no bojo da TRI/TRIT, tendo como corolário a crise do Estado do BemEstar, o advento do neoliberalismo, o acelerar do progresso tecnológico e a redefinição da ordem econômica/geopolítica mundial, marcada pela ascensão dos países emergentes da Semiperiferia (Brasil, China, Índia, Rússia, etc.), que conduzirá a um novo ordenamento a nível do sistema "Núcleo Orgânico Central-Semiperiferia-Periferia». Em alguns desses países já existem experiências maduras do ponto de vista alternativo-energético e energéticorenovável, notadamente no que diz respeito à biomassa, como é o caso, por exemplo, do Brasil (álcool e biodiesel). A adoção de caminhos sustentáveis, do ponto de vista do suporte energético-tecnológico-produtivo de suas pujantes/dinâmicas economias, consolida-se no Brasil e ganha espaço na Índia e na China. Portanto, o novo desenho da ordem econômica internacional, marcado por redefinições de cunho geográfico-industrial, produtivo-locacional e ascencional-tecnológico, firmará a transição do Paradigma dos Combustíveis Fósseis para o Paradigma das Fontes Renováveis de Energia.

Conforme é assinalado por COSTA e RODRIGUES (2010, pp. 10 e 11), os choques petrolíferos da década de 1970 assinalam que o paradigma petrolífero começa a dar sinais de esgotamento. Logo, a formação de uma maior consciência com relação aos problemas afectos à ecologia conduzem (muitas vezes de forma equivocada e até fundamentalista) à abordagem crescente dos temas relacionados ao meio ambiente. O quê se configura é que a questão ambiental não pode ser tratada separadamente da questão energética. Portanto, pode-se considerar que se vive hoje uma transição do Paradigma dos Combustíveis Fósseis (energéticos não renováveis) para o Paradigma das Energias Renováveis. Neste contexto, as fontes energéticas alternativas irão aumentando gradualmente seu nível de participação em termos da base energético-produtiva, podendo-se mesmo recorrer a determinados recursos energéticos não renováveis, como é o caso do gás natural, menos poluente do que o petróleo e seus derivados e sofisticador de processos e tecnologias. 
Logo, a transição paradigmática será marcada pela introdução de novas fontes energéticas, pela convivência/combinação e interação destas com as fontes energéticas tradicionais, ou seja, pela diversificação crescente da matriz energética, e por um crescente mix de fontes energéticas (gestão estratégica da matriz energética).

A mudança de paradigma energético-ambiental, consoante o que é colocado por COSTA E RODRIGUES (2010, pp. 10 - 12), por levar ainda algumas (ou mesmo várias) décadas a se efetivar, representará a entrada em cena de todo um imenso manancial de tecnologias de uso final e de processo. Com isso, inúmeros e interessantes arranjos tecnológico-produtivos poderão vir a ser implementados. Assim sendo, tomando-se como exemplo o caso brasileiro, a transição do Paradigma dos Combustíveis Fósseis (petróleo) para o Paradigma das Fontes Renováveis de Energia (com destaque para a biomassa), será intermediada pelo gás natural e pela interação/combinação de combustíveis representativos dos dois paradigmas em questão. Por conseguinte, abre-se espaço, no contexto dos países da Periferia/Semiperiferia, para um significativo manancial de alternativas energéticas que ultrapassam, por exemplo. as possibilidades abertas por certas opções (solar e eólica, por exemplo) e que se calcam principalmente na biomassa.

Por outro lado, e isto é mais flagrante no caso das grandes metrópoles e megalópoles da Periferia/Semiperiferia (São Paulo, Mumbay, Calcutá, Cidade do México, etc.), o novo paradigma energético-ambiental passa pelo (re)aproveitamento econômico-conservacionista dos resíduos sólidos urbanos a partir da reciclagem e também pelo tratamento de águas/esgotos, que para além de contrariar a lógica consumista-desperdiçadora e 0 matiz de degradação ambiental do paradigma transato, contribui, de forma significativa, para a produção energético-alternativa (notadamente de gás metano), em muito colaborando para 0 estabelecimento de cidades/metrópoles autosustentáveis (um dos pilares do novo paradigma energético-ambiental). Por outro lado, a nível da transição energético-ambiental, ganha importância fundamental a questão da conservação e do uso racional de energia. A conservação de energia deve, inclusive, no âmbito do novo paradigma energético-ambiental, bem como na fase de transição interparadigmática, ser considerada como recurso energético. A conservação/racionalização de energia deve ser vista sob dois prismas básicos, a saber: 0 das fontes energéticas e o dos segmentos de consumo (COSTA, 1990, p. 367). A conservação/racionalização de energia articula-se, de entre outros aspectos, com a mudança nos hábitos de consumo, um dos pontos básicos do novo paradigma energético-ambiental, capaz de viabilizar a ultrapassagem do modelo energívoro. 


\section{CONSIDERAÇÕES FINAIS}

Desse modo, configura-se o cenário no qual deverá atuar a Educação Ambiental, marcado por uma fortíssima instabilidade e volatilidade, fruto da referida transição paradigmática, da ocorrência da TRI/TRIT, da hegemonia dos cânones neoliberais e da nova configuração da ordem econômica mundial. Este conjunto de elementos condiciona fortemente o papel da Educação Ambiental, as metodologias a ela afetas e o seu potencial como elemento pedagógico de conscientização de hábitos e atitudes sócio-culturais perante a transição paradigmática e o paradigma energético-ambiental vindouro.

\section{REFERÊNCIAS BIBLIOGRÁFICAS}

BERTALANFFY, L. V. (2008): Teoria Geral dos Sistemas: Fundamentos, Desenvolvimentos e Aplicações. Petrópolis. Vozes,

CAZADERO, M. (1995): Las revoluciones industriales. México. FCE.

CHIAVENATO, I. (1993): Teoria Geral da Administração: Abordagens Prescritivas e Normativas da Administração - Volume 1. São Paulo. Makron Books.

COSTA, F. C. e HOESCHL. H. C. (2006): Gestão do Conhecimento na Cadeia Produtiva de Biodiesel [Em Linha]. Disponível em «http://www.biodiesel.gov.br/docs/congressso2006/agricultura/GestaoConheci mento.pdf» [Consultado em 08/04/2010], pp. $30-34$.

COSTA, F. J. P. (1990): O Papel da Conservação nas Políticas e Programas Direcionados ao Setor Energético. Rio de Janeiro. COPPE/UFRJ. Dissertação de Mestrado, $750 \mathrm{pp}$.

COSTA, F. J. P. E RODRIGUES, M. G. (2010): Governança, Meio Ambiente e Transição de Paradigmas. Área Temática de Gestão Social e Ambiente. VII Simpósio de Excelência em Gestão e Tecnologia (VII SEGet). Resende. AEDB, de 20 a 22 de Outubro de 2010.

COSTA, F. J. P. E RODRIGUES, M. G. (2009): O Planejamento Ambiental e a Gestão do Território no contexto do Planejamento Estratégico. I Congresso Lusófono sobre Ambiente e Energia. Centro de Congressos do Estoril Cascais (Estoril), de 20 a 22 de Setembro de 2009.

FREITAS, S. M. (2007): Protocolo de Kyoto: uma reflexão sobre o aquecimento global [Em Linha]. Disponível em «http://www.iea.sp.gov.br/out/verTexto.php?codTexto=8763». [Consultado em 
06/04/2010]. Análises e Indicadores do Agronegócio. Volume 2, n. 3. Março de 2007. São Paulo. IEA.

OLIVEIRA, M. J. E VECCHIA, F. (2009): A Controvérsia das Mudanças Climáticas e do Aquecimento Global Antropogênico: Consenso Científico ou

Interesse Político? Fórum Ambiental da Alta Paulista. Volume V. Ano 2009. Tupã. ANAP, pp. $946-962$.

SANTOS, T. (1983): Revolução Científico-Técnica e Capitalismo Contemporâneo. Petrópolis. Vozes.

SINGER, P. (1998): Uma Utopia Militante: Repensando o Socialismo. Petrópolis. Vozes.

SOUZA, J. N. S. E BENEVIDES, R. C. A. (2005): Educação Ambiental Para o Desenvolvimento Sustentável e 0 Comprometimento das Universidades/Faculdades do Município do Rio de Janeiro, RJ. II Simpósio de Excelência em Gestão e Tecnologia (II SEGet). Resende. AEDB, pp. 531 548.

TEIXEIRA, M. A. (2003): Caracterização Energética do Babaçú e Análise do Potencial de Cogeração. Tese de Doutorado. Faculdade de Engenharia Mecânica. Universidade Estadual de Campinas. Campinas, 189 pp. 
